\title{
Photocatalytic properties of a palladium metallosquare with encapsulated fullerenes via singlet oxygen generation
}

\author{
Víctor Martínez-Agramunt ${ }^{\mathrm{a}}$ and Eduardo Peris ${ }^{\mathrm{a}}$ \\ anstitute of Avanced Materials (INAM). Centro de Innovación en Química Avanzada (ORFEO-CINQA). Universitat \\ Jaume I. Av. Vicente Sos Baynat s/n. Castellón. E-12071. Spain.
}

\begin{abstract}
Singlet oxygen has won recently a great deal of attention due to its strong oxidizing properties, which makes it useful in organic synthesis and biological studies. However, the photosensitizers that are required for singlet oxygen generation remain inadequate due to their often low thermal and photochemical stabilities. Here we describe the use of a palladium-conjoined metallosquare with encapsulated fullerenes $\left(\mathrm{C}_{60}\right.$ or $\left.\mathrm{C}_{70}\right)$, which behaves as an efficient and photochemically stable singlet oxygen photosensitizer. The metallocage with the encapsulated fullerenes is able to oxidize a series of cyclic and acyclic alkenes at room temperature via visible light-induced singlet oxygen generation, using oxygen molecules in air at atmospheric pressure. These reactions take advantage of the excellent spin-converting properties of fullerenes, which make them excellent agents for singlet oxygen production.
\end{abstract}

\section{Introduction}

Singlet oxygen is widely recognized due to its reactivity with alkenes, ${ }^{1}$ as well as its involvement in clinical photodynamic therapy treatment (PDT) of tumors. ${ }^{2}$ Photocatalyzed reactions involving singlet oxygen constitute an effective way for compound oxidation, ${ }^{3}$ and for synthesizing oxygenated structures by facilitating carbon-oxygen and heteroatom-oxygen bond formation 4 with high atom economy and low cost. Singlet $\mathrm{O}_{2}$ $\left({ }^{1} \Delta_{\mathrm{g}}\right)$ is conventionally generated by energy transfer from a photosensitizer to triplet $\mathrm{O}_{2}\left(3 \Sigma_{\mathrm{g}}\right) .3 \mathrm{~b}, 5$ Normally, the photosensitizers are organic dyes that are prone to photoinduced or enzymatic degradation, therefore with limited applicability in PDT protocols and in organic synthesis. Searching for highly efficient photosensitizers with large absorption coefficients and high photochemical stability is currently one of the main challenges for widening the applications of single oxygen in organic synthesis and therapeutic research. Fullerenes $\left(C_{60}\right.$ and $C_{70}$ ) have shown to be efficient photosensitizers for singlet oxygen generation, ${ }^{6}$ but their poor solubility in most common solvents makes them unsuitable for an extensive applicability. This problem has been addressed by some researchers by functionalizing the fullerene core with solubilizing groups, 7 a method that is hampered by the low product yields obtained and by the need of using complicated reaction procedures. In addition, fullerene-containing systems have also been widely used for light-harvesting and energy conversion, ${ }^{8}$ because the strong UV/Vis absorption together with the large size and symmetrical shape of fullerenes facilitates electron transfer events with applications in light-induced processes. This, in part, explains why research on fullerene receptors based on non-covalent bonding interactions is gaining interest in recent years. 9 We recently contributed to the design of a series of organometallic-based receptors for the encapsulation of fullerenes by using metallosupramolecular structures with di$\mathrm{N}$-heterocyclic carbene (NHC) ligands connected by rigid $\pi$ conjugated polyaromatic systems. ${ }^{10}$ Compared to the most widely used Werner-type metallosupramolecular assemblies, ${ }^{11}$ organometallic-based supramolecular coordination complexes supported by $\mathrm{N}$-heterocyclic carbene ligands ${ }^{12}$ have the advantage of their higher stability, which is arguably attributed to the strength of the $\mathrm{M}-\mathrm{C}_{\text {carbene }}$ bond. In one of our most recent contributions, ${ }^{10 \mathrm{C}}$ we described a palladium-cornered metallosquare supported by a pyrene-di-midazolylidene ligand, which showed very high affinities for fullerenes $\mathrm{C}_{60}$ and $\mathrm{C}_{70}$ (Scheme 1 ). Given the high solubility ( $>10 \mathrm{mM}$ in organic solvents such as $\mathrm{CH}_{3} \mathrm{CN}, \mathrm{CH}_{2} \mathrm{Cl}_{2}, \mathrm{CHCl}_{3}$, etc.) and stability of this complex and its related host:guest adducts with encapsulated fullerenes, we thought that we could take advantage of the spin transfer properties of the encapsulated fullerenes for finding their applicability in challenging organic transformations.

In this study we describe the use of the fullerene host:guest complexes $\mathrm{C}_{60} @ 1$ and $\mathrm{C}_{70} @ \mathbf{1}$, as photosensitizers for the generation of singlet $\mathrm{O}_{2}$, and for facilitating carbon-oxygen bond forming reactions with a variety of organic substrates.
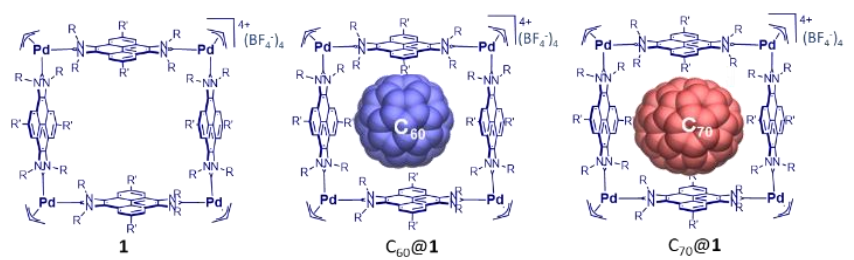

Scheme 1. Fullerene-containing metallocages used in this study 


\section{Results and discussion}

We first analysed the photophysical properties of 1, $\mathrm{C}_{60} @ \mathbf{1}$ and $\mathrm{C}_{70} @ \mathbf{1}$ by studying their electronic and emission spectra. The UV-vis spectra of $\mathrm{C}_{60} @ \mathbf{1}$ and $\mathrm{C}_{70} @ \mathbf{1}$ show a weak absorption band beyond $500 \mathrm{~nm}$ (see ESI). This band (not observed in the UV-vis spectrum of $\mathbf{1}$ ) is assigned to $S_{o} \rightarrow S_{n}$ transitions of the fullerenes. The spectra also show the bands due to the absorption of the pyrene moieties of the bridging ligands of the complex, between 300 and $360 \mathrm{~nm}$. The photoinduced energy transfer of the host:guest complexes was analysed by luminescence studies. Complex 1 alone gives intense fluorescence due to the emission of the pyrene fragment, with a vibronicallyresolved band with a maximum at $405 \mathrm{~cm}^{-1}$. This band is quenched in $\mathrm{C}_{60} @ \mathbf{1}$ and $\mathrm{C}_{70} @ \mathbf{1}$, indicating energy transfer from the host to the fullerene.

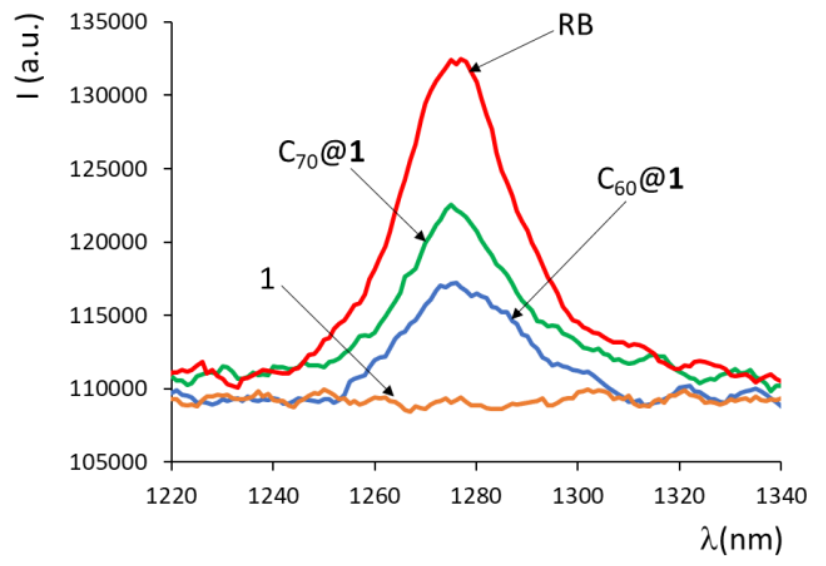

Figure 1. Near infrared singlet oxygen phosphorescent emission spectra sensitized by Rose Bengal (RB), 1, $\mathrm{C}_{60} @ \mathbf{1}$ and $\mathrm{C}_{70} @ 1\left(1.25 \mathrm{X10}^{-4} \mathrm{M}\right.$ in $\left.\mathrm{CH}_{3} \mathrm{CN}, \lambda_{\mathrm{ex}}=532 \mathrm{~nm}\right)$.

The evaluation of the photosensitizing efficiency of $\mathrm{C}_{60} @ \mathbf{1}$ and $\mathrm{C}_{70} @ 1$ was carried out in acetonitrile, by measuring the phosphorescence emission spectra of singlet oxygen generated by the photosensitizer upon irradiation with visible light. The near-infra-red (NIR) phosphorescence serves as a direct and unambiguous marker for the existence of ${ }^{1} \mathrm{O}_{2}{ }^{2 b}$, 5a, 5b Photoirradiated samples of $\mathrm{C}_{60} @ \mathbf{1}$ and $\mathrm{C}_{70} @ \mathbf{1}$ in aerated acetonitrile, clearly showed the $\mathrm{NIR}{ }^{1} \mathrm{O}_{2}$ luminescence around 1270 $\mathrm{nm}$ upon excitation with $532 \mathrm{~nm}$ laser light (Figure 1). Under the same conditions, the empty cage 1 did not produce any measurable phosphorescence. We estimated a ${ }^{1} \mathrm{O}_{2}$ quantum yield of $\Phi_{\Delta}=0.23$ and 0.41, for $C_{60} @ 1$ and $C_{70} @ 1$, respectively, by comparing the integrated areas determined for the samples and Rose Bengal used as standard $\left(\Phi_{\Delta}=0.71\right) .{ }^{13}$ These $\Phi_{\Delta}$ values for the inclusion complexes are considerably lower than those reported for $\mathrm{C}_{60}$ and $\mathrm{C}_{70}$ (in $\mathrm{C}_{6} \mathrm{H}_{6}$ ), which are known to be very close to unity. ${ }^{14} \mathrm{~A}$ possible explanation for this may be the quenching of ${ }^{1} \mathrm{O}_{2}$ by the complex before it can escape the solvent cage, but most likely it is due to reduction of the sentitizer-to-oxygen energy transfer efficiency as a consequence of the energy-transfer interactions between the fullerenes and the host. It should be mentioned that in a pioneer work by
Prat and co-workers, a 1:2 fullerene:cyclodextrin inclusion complex was prepared that was able to preserve the ability of $\mathrm{C}_{60}$ for singlet oxygen production, despite the efficiency was reduced in about $50 \%$ with respect to free $C_{60}$, an observation that the authors attributed to fast energy transfer between the fullerene and the host. ${ }^{15}$

It is interesting to note that $C_{70}$ is generally preferred as sensitizer over $\mathrm{C}_{60}$, due to its enhanced visible light absorption, as consequence of the relaxation in the symmetry from $I_{\mathrm{h}}\left(\mathrm{C}_{60}\right)$ to $D_{5 \mathrm{~h}}\left(\mathrm{C}_{70}\right)$ point group symmetries. Accordingly, the transitions that are symmetry-forbidden for $C_{60}$ are allowed for $C_{70} \cdot{ }^{16}$ In the case of $\mathrm{C}_{60} @ \mathbf{1}$, the encapsulation of $\mathrm{C}_{60}$ in the metallosquare may reduce the symmetry of the fullerene, therefore increasing the intensity of its low energy absorption bands, which, in turn, produces an enhanced photosensitizing character compared to free $\mathrm{C}_{60}$.

Given the efficient production of ${ }^{1} \mathrm{O}_{2}$ by photosensitizers $\mathrm{C}_{60} @ 1$ and $\mathrm{C}_{70} @ \mathbf{1}$, we decided to study if we could use these two compounds in photocatalytic reactions involving the formation of endoperoxides by cycloaddition of ${ }^{1} \mathrm{O}_{2}$ with dienes. Endoperoxides are often active biological active reagents ${ }^{17}$ that are used as intermediates in a large number of organic transformations. ${ }^{18}$ In addition, the synthesis of natural products is often modeled on possible ${ }^{1} \mathrm{O}_{2}$ biosynthetic routes, thus biomimetic reactions singlet oxygen reactions that use alkene and diene precursors are receiving increasing interest during the last few years. ${ }^{1 c}$, $3 a$ As a first model reaction, we studied the endoperoxidation of anthracene to analyse the potential use of our photosensitizers in carbon-oxygen bond forming reactions. At this point it is important to mention that there is one very recent example of a metallosupramolecular assembly used as photosensitizer for the light-induced [4+2] cycloaddition of anthracene with singlet oxygen. ${ }^{19}$ Although this report constitutes the only published example of a metallosupramolecular system used for light-induced cycloaddition of ${ }^{1} \mathrm{O}_{2}$, the cage showed to be photolabile and eventually decomposed, therefore providing very limited applicability. We prepared solutions of $0.5 \mathrm{mM}$ of anthracene in deuterated acetonitrile in the presence of different amounts of $\mathrm{C}_{60} @ \mathbf{1}$ and $\mathrm{C}_{70} @ \mathbf{1}$, and irradiated them at 633 (red) and 512 (green) nm with a household RGB LED light ( $0.07 \mathrm{~mW} / \mathrm{cm}^{2}$ incident power). The reaction could be easily monitored by ${ }^{1} \mathrm{H}$ NMR spectroscopy. Only the reaction carried out under irradiation of green light showed evolution to the formation of 9,10-dihydro-9,10-epidioxyanthracene. The absence of reactivity under red light irradiation can be explained due to the negligible absorption of the two complexes at this wavelength (see Figure S21 in the $\mathrm{SI}$ ). Figure 2 shows the time-dependent evolution of anthracene conversion to anthracene endoperoxide in the presence of Rose Bengal, $C_{60} @ \mathbf{1}$ and $C_{70} @ 1$. As can be observed, for the reactions carried out with $0.05 \mathrm{mM}$ of the photosensitizers, the reaction is faster when $C_{70} @ \mathbf{1}$ is used, although $C_{60} @ \mathbf{1}$ is also very efficient. Under these conditions, the reaction is complete after 65 min when $C_{70} @ \mathbf{1}$ is used, while the same concentration of $\mathrm{C}_{60} @ 1$ needs 90 min for completing the reaction. Reducing the concentration of the sensitizer results in a decrease of the reaction rate, although using $5 \mathrm{X1O}^{-4} \mathrm{mM}$ of $\mathrm{C}_{70} @ 1$ (which represents a loading of $0.1 \mathrm{~mol} \%$ with respect to the amount of substrate), still produces full conversion in just 4 hours. Interestingly, the activity of the supramolecular sensitizer is maintained constant all over the reaction course, 
therefore illustrating its stability under the reaction conditions used. The reaction carried out with Rose Bengal showed a higher initial reaction rate, but after 20 min the reaction proceeded slower, probably due to partial photobleaching of the dye. All the reactions proceeded following a pseudo-first order kinetics with respect to the substrate. This allowed us to calculate the reaction rates with all three sensitizers, and to estimate the singlet oxygen quantum yields of $C_{60} @ 1$ and $C_{70} @ 1$ from Equation 1. In this equation $\phi_{\Delta}(\mathrm{RB})$ is the singlet oxygen quantum yield for Rose Bengal (o.71), and $\mathrm{W}$ and $\mathrm{W}_{\mathrm{RB}}$ are the reaction rates for the endoperoxidation of anthracene in the presence of the fullerene inclusion complex and Rose Bengal, respectively. By this method the quantum yields for $\mathrm{C}_{60} @ \mathbf{1}$ and $\mathrm{C}_{70} @ 1$ were 0.28 and 0.40, in excellent agreement with the values obtained from Figure 1.

$$
\phi_{\Delta}=\phi_{\Delta}(\mathrm{RB}) \frac{\mathrm{W}}{\mathrm{W}_{\mathrm{RB}}}
$$

The stability of the photosensitizers along the reaction can also be confirmed by monitoring the signals due to the protons of the pyrene moiety of the di-NHC ligand of the metallocage, whose integral remained constant with respect to the standard all along the reaction course (see, for example, the spectra shown in Figures $\mathrm{S}_{4}, \mathrm{~S}_{7}, \mathrm{~S}_{10}, \mathrm{~S}_{11}$ and $\mathrm{S}_{19}$ in ESI). This stability of the complexes under the conditions of the reaction is an obvious advantage of these systems compared to the widely used highly conjugated organic photosensitizers, such as Rose Bengal or methylene blue, ${ }^{2 \mathrm{~d},}{ }^{20}$ for which the production of singlet oxygen destroys conjugation and with it the ability to absorb visible light (photobleaching).

Fullerenes $\mathrm{C}_{60}$ or $\mathrm{C}_{70}$ alone did not produce any anthracene endoperoxide, and $\mathbf{1}$ alone only produced a $2 \%$ conversion after 15 hours. This can be explained by the lack of absorption of visible light by 1 (see Figure S2o), and the extremely low solubility of fullerenes in acetonitrile. ${ }^{21}$

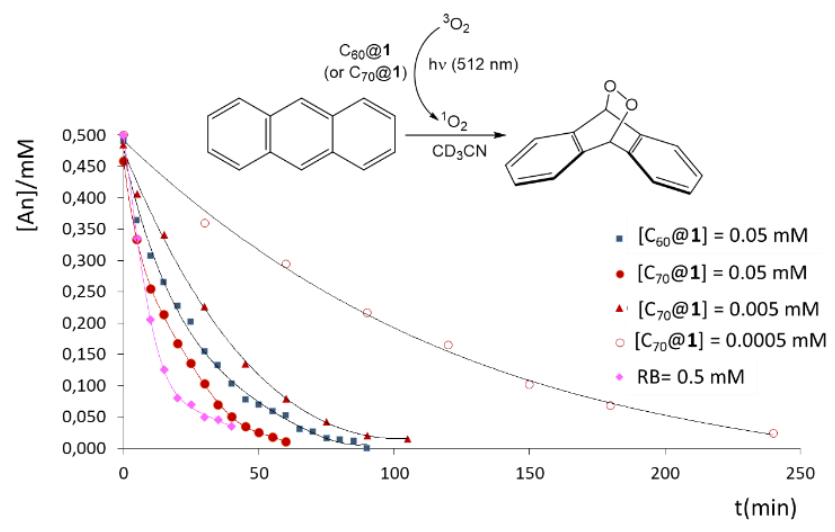

Figure 2. Time-dependent reaction profile of the endoperoxidation of anthracene using Rose Bengal, $\mathrm{C}_{60} @ 1$ and $\mathrm{C}_{70} @ 1$ as photosensitizers. Reactions performed in aeriated $\mathrm{CD}_{3} \mathrm{CN}$ under irradiation at $512 \mathrm{~nm}$ and $0.07 \mathrm{~mW} / \mathrm{cm}^{2}$ incident power. The reactions were monitored by ${ }^{1} \mathrm{H}$ NMR spectroscopy. All reactions using initial concentrations of anthracene of 0.5 $\mathrm{mM}$.

To explore the substrate scope of our metallosupramolecular photosensitizers, a series of cyclic and acyclic alkenes were subjected to photo-irradiation in the presence of air and $\mathrm{C}_{60} @ 1$ or $C_{70} @ 1$. For these reactions we used a LED lamp with 3
$\mathrm{mW} / \mathrm{cm}^{2}$ of incident power. The seven substrates were chosen to explore their different reactivities and the tolerance to functional groups. Some of these substrates are prone to react with singlet oxygen to produce the corresponding endoperoxides via a photo-induced Diels-Alder reaction in which the oxygen is the dienophile (for substrates 2, 3, 4, 5, 7 and 8). Substrates 6 and 8 react through an ene reaction, and yields an allylic hydroperoxide in which the double bond of the substrate has shifted to a position adjacent to the original double bond. The mechanistic aspects of these reactions have been studied in detail. ${ }^{22}$ The reactions were performed at room temperature, in an NMR tube filled with a solution of the substrate and the photosensitizer in $\mathrm{CD}_{3} \mathrm{CN}$, so that the evolution of the process could be easily monitored by ${ }^{1} \mathrm{H}$ NMR spectroscopy. Table 1 shows the substrates used and the resulting products, together with the product yields obtained under the reaction conditions used. The table includes some of the control experiments that we performed when we performed the endoperoxidation of anthracene in the absence of catalysts (entry 1 ), or in the presence of $C_{60}$ or $C_{70}$ alone. As can be observed (entries 1-3), these reactions did not produce any amount of product even after 24 hour of reaction. The Table includes the product yields at the time when full conversion of the substrate is achieved. The two photosensitizers were very active in the endoperoxidation of 9,10-diphenylanthracene (DPA, 3), yielding the corresponding endoperoxide quantitatively $[\mathbf{3}(\mathbf{O}-\mathbf{O})]$ in just 30 minutes (entries 8 and 9). For the rest of the substrates, $C_{70} @ 1$ was found more active than $C_{60} @ 1$. In the endoperoxidation of 1,3-cyclohexadiene (4), $\mathrm{C}_{60} @ 1$ afforded 68\% yield of product in one hour, while $\mathrm{C}_{70} @ \mathbf{1}$ yielded 77\%, and quasi-quantitative yield after 24 hours. $\mathrm{C}_{70} @ \mathbf{1}$ facilitated the endoperoxidation of 1,3 -cyclooctadiene yielding $86 \%$ of the endoperoxide $\mathbf{5}(\mathbf{O}-\mathbf{O})$ in $24 \mathrm{~h}$, while under the same conditions $\mathrm{C}_{60} @ 1$ afforded a negligible amount of product (compare entries 15 and 17). Similarly, in the reaction of cyclohexene to produce cyclohexenyl hydroperoxide $[\mathbf{6}(\mathbf{O}-\mathbf{O})] \mathrm{C}_{70} @ \mathbf{1}$ generated the product in 75\% yield after 24 hours, while $\mathrm{C}_{60} @ 1$ only yielded $5 \%$ (compare entries 18 and 19). The cycloaddition of oxygen to 1,4-diphenyl butadiene (7) produced the cyclic endoperoxide 7(O-O) in 95\% yield when $\mathrm{C}_{70} @ \mathbf{1}$ was used, but only $72 \%$ of product was formed for the reaction carried out with $\mathrm{C}_{60} @ \mathbf{1}$ (entries 20 and 21). Finally, the photooxidation of hexamethyl benzene to the epidioxy hydroperoxide $8(\mathbf{O}-\mathbf{O})$ was produced in $71 \%$ yield after 2 hours for the reaction carried out with $\mathrm{C}_{70} @ \mathbf{1}$, while the reaction performed with $\mathrm{C}_{60} @ \mathbf{1}$ just generated $7 \%$ of product (entries 22 and 23). This latter reaction consumes two molecules of singlet oxygen, and is known to proceed via a two-step process involving a [4+2] cycloaddition followed by an ene-reaction. ${ }^{23} \mathrm{~A}$ point that is worth mentioning is that the yields of the products for the reactions carried out with substrates 5, 6 and 8, do not simply reflect the differences in quantum yield production of singlet oxygen by $\mathrm{C}_{60} @ 1$ and $\mathrm{C}_{70} @ 1$. Although we did not make detailed mechanistic studies, it may be possible that the weaker binding of $\mathrm{C}_{60}$ in $\mathrm{C}_{60} @ \mathbf{1}$ (compared to the affinity of $\mathrm{C}_{70}$ in $\left.\mathrm{C}_{70} @ \mathbf{1}\right)^{10 \mathrm{c}}$ makes that the fullerene is partially replaced by the substrate or the product in the course of the reaction, and this may justify the unexpected decrease of the reaction yields. 
Table 1. Peroxidation of organic substrates by light-induced cycloaddition of ${ }^{1} \mathrm{O}_{2}$. ${ }^{\text {a }}$ Substrate scope.

\begin{tabular}{|c|c|c|c|c|}
\hline $\begin{array}{l}\text { En- } \\
\text { try }\end{array}$ & Substrate/Product & Cat. & $\begin{array}{l}\text { Time } \\
\text { (h) }\end{array}$ & $\begin{array}{l}\text { Yield } \\
(\%)^{b}\end{array}$ \\
\hline 1 & & none & 24 & o \\
\hline 2 & & $\mathrm{C}_{6 \mathrm{o}}$ & 24 & o \\
\hline 3 & & $\mathrm{C}_{70}$ & 24 & o \\
\hline 4 & & $\mathrm{C}_{60} @ \mathbf{1}$ & 0.5 & 69 \\
\hline 5 & & $\mathrm{C}_{60} @ \mathbf{1}$ & 1 & $>99$ \\
\hline 6 & & $\mathrm{C}_{70} @ \mathbf{1}$ & 0.5 & 75 \\
\hline 7 & & $\mathrm{C}_{70} @ \mathbf{1}$ & 1 & $>99$ \\
\hline 8 & & $\mathrm{C}_{60} @ \mathbf{1}$ & 0.5 & $>99$ \\
\hline 9 & & $\mathrm{C}_{70} @ \mathbf{1}$ & 0.5 & $>99$ \\
\hline $10^{c}$ & & $\mathrm{C}_{60} @ \mathbf{1}$ & 1 & 68 \\
\hline $11^{\mathrm{c}}$ & & $\mathrm{C}_{60} @ \mathbf{1}$ & 24 & 81 \\
\hline $12^{\mathrm{C}}$ & & $\mathrm{C}_{70} @ \mathbf{1}$ & 1 & 77 \\
\hline $13^{\mathrm{c}}$ & & $\mathrm{C}_{70} @ \mathbf{1}$ & 24 & 92 \\
\hline $14^{\mathrm{c}}$ & & $\mathrm{C}_{60} @ \mathbf{1}$ & 1 & o \\
\hline $15^{c}$ & & $\mathrm{C}_{60} @ \mathbf{1}$ & 24 & 5 \\
\hline $16^{c}$ & & $\mathrm{C}_{70} @ \mathbf{1}$ & 1 & 10 \\
\hline $17^{c}$ & & $\mathrm{C}_{70} @ \mathbf{1}$ & 24 & 86 \\
\hline $18^{c}$ & & $\mathrm{C}_{60} @ \mathbf{1}$ & 24 & 5 \\
\hline $19^{c}$ & 6 & $\mathrm{C}_{70} @ \mathbf{1}$ & 24 & 82 \\
\hline $2 \mathrm{O}^{\mathrm{d}}$ & & $\mathrm{C}_{60} @ \mathbf{1}$ & 12 & 72 \\
\hline $21^{\mathrm{d}}$ & 7 & $\mathrm{C}_{70} @ \mathbf{1}$ & 12 & 95 \\
\hline $22^{d}$ & & $\mathrm{C}_{60} @ \mathbf{1}$ & 2 & 7 \\
\hline $23^{d}$ & $8(0-c$ & $\mathrm{C}_{70} @ \mathbf{1}$ & 2 & 71 \\
\hline
\end{tabular}

a Reaction conditions: Reactions carried out in in $\mathrm{CD}_{3} \mathrm{CN}$ in an NMR tube with $1 \mathrm{mM}$ of substrate and $0.05 \mathrm{mM}$ of photosensitizer. ${ }^{b}{ }^{1} \mathrm{H}$ NMR yields, using anisole $(1 \mathrm{mM})$ as internal integration standard. ${ }^{c_{2}} \mathrm{mM}$ of substrate and $0.1 \mathrm{mM}$ of photosensitizer. ${ }^{\mathrm{d}} 5 \mathrm{mM}$ of substrate and $0.25 \mathrm{mM}$ of photosensitizer. Samples were irradiated with a LED lamp (3 $\left.\mathrm{mW} / \mathrm{cm}^{2}\right)$.

We find important to point out that many of the products obtained from these reactions are important reaction intermediates that have been used for the synthesis of several natural products and commercially valuable materials, therefore their high yielding preparation constitutes a matter of great interest. For example, $\mathbf{4}(\mathbf{O}-\mathbf{O})$ is the first reaction intermediate used in the preparation of teucrolivin $\mathrm{A}^{24}$ and toxocarol. ${ }^{25}$ The cyclooctene endoperoxide $\mathbf{5}(\mathbf{O}-\mathbf{O})$ has recently been used for the preparation of 1,2-diaminocyclooctanediols ${ }^{26}$ and 4-hydroxyenones, ${ }^{27}$ and for the total synthesis of (+)-dubiusamine $\mathrm{A}(\mathbf{1}) .{ }^{28}$ Cyclohexene hydroperoxide $(\mathbf{6}(\mathbf{O}-\mathbf{O}))$ is a key starting reagent in the production of nylon- 6 and nylon- 6,6 polyamides. ${ }^{29}$ The endoperoxide $\mathbf{7}(\mathbf{O}-\mathbf{O})$ is an intermediate in the biosynthetically inspired route to diphenyl furan and furan fatty acids, $3^{30}$ and for the asymmetric synthesis of fused butyrolactones. $3^{1}$

\section{Conclusions}

In conclusion, by taking advantage of the excellent spin-converting properties of fullerenes, we used our fullerene-containing host:guest complexes as photosensitizers for the generation of singlet $\mathrm{O}_{2}$. Both $\mathrm{C}_{60} @ \mathbf{1}$ or $\mathrm{C}_{70} @ \mathbf{1}$ were found to be very effective photosensitizers for the peroxidation of a broad variety of cyclic and acyclic alkenes under air atmosphere. While supramolecular photochemistry has recently been highlighted as a potential powerful synthetic tool, 32 the examples in which supramolecular assemblies are used for promoting photocycloadditions are restricted to their participation as hosts or templates for facilitating the solubilization of the organic substrates in water. To the best of our knowledge, this is the first time that a host:guest supramolecular assembly is used for the peroxidation a variety of organic substrates. Our findings go beyond the results that we describe in this work, because they underline the possibility that other fullerenecontaining host-guest supramolecular systems have the potential to be used for similar photocatalytic reactions, therefore opening a venue for future research. Also important is the potential implications of this study in the use of fullerene-encapsulated supramolecular systems in the development of agents for clinical photodynamic therapy treatment (PDT). Research in these directions are currently being developed in our laboratory.

\section{Experimental section}

\section{General Comments}

The preparation of the palladium-cornered metallo-square $\mathbf{1}$ was performed according to the literature method. ${ }^{10}$ Anhydrous solvents were dried using the Solvent Purification System (SPS M BRAUN) or purchased and degassed prior to use. All other reagents were used as received from commercial suppliers. NMR spectra were recorded on a Varian Innova 500 $\mathrm{MHz}$ or on a Bruker $400 / 300 \mathrm{MHz}$. NMR spectra were recorded at room temperature with $\mathrm{CD}_{3} \mathrm{CN}$ as solvent. All values of the chemical shift are in ppm regarding the $\delta$-scale. UV/Visible absorption spectra were recorded on a Varian Cary $300 \mathrm{BIO}$ spectrophotometer using acetonitrile under ambient conditions. Emission spectra were recorded on a modular Horiba FluoroLog-3 spectrofluorometer employing degassed acetonitrile. As an example, the following paragraph describes the general procedure used for the endoperoxidation of anthracene. The details about the photocatalytic reactions carried out with all other substrates are given in the Supplementary Information.

Photocatalytic Endoperoxidation of Anthracene with Fullerene@1

All experiments were performed in NMR tubes with $\mathrm{CD}_{3} \mathrm{CN}$ and a previous sonication for 12 hours of host solution (complex 1) and the respective fullerene. The samples were irradiated with green light $(\lambda=512 \mathrm{~nm})$, with a $3.5 \mathrm{~W}$ household RGB-LED light $\left(0.07 \mathrm{~mW} / \mathrm{cm}^{2}\right.$ incident power). The initial concentration of anthracene concentration was $0.5 \mathrm{mM}$ in all experiments, while Fullerene@1 concentration was set to 0.05 $\mathrm{mM}$ (10 mol\% cat), $0.005 \mathrm{mM}$ (1 mol\% cat) and $0.0005 \mathrm{mM}$ (o.1 mol\% cat). The experiments were carried out placing the NMR tube at $10 \mathrm{~cm}$ of the light beam, under the exclusion from other light sources by a black box. NMR sample was protected from ambient light between the measurements. The advance of the reaction was monitored by ${ }^{1} \mathrm{H}$ NMR spectroscopy. 


\section{ASSOCIATED CONTENT}

Supporting Information. Supplementary information accompanies this paper, including all experimental details, NMR spectra, Uv/vis and emission spectra related to the work. This material is available free of charge via the Internet at http://pubs.acs.org.

\section{AUTHOR INFORMATION}

\section{Corresponding Author}

* eperis@uji.es

\section{Author Contributions}

V.M.-A. performed all the catalytic experiments and contributed to the writing of the article. E.P. designed the experiments, directed the study and wrote the first version of the manuscript. Both authors discussed the results and accepted the final version of the article.

\section{Funding Sources}

Universitat Jaume I (UJI-B2017-07)

\section{ACKNOWLEDGMENT}

We gratefully acknowledge financial support from the Universitat Jaume I (UJI-B2017-07). V. M.-A. thanks the Generalitat Valenciana for a $\mathrm{PhD}$ fellowship We are grateful to the Serveis Centrals d'Instrumentació Científica (SCIC-UJI) for providing with spectroscopic facilities.

\section{REFERENCES}

1. (a) Hoffmann, N., Photochemical reactions as key steps in organic synthesis. Chem. Rev. 2008, 108 (3), 1052-1103; (b) Singleton, D. A.; Hang, C.; Szymanski, M. J.; Meyer, M. P.; Leach, A. G.; Kuwata, K. T.; Chen, J. S.; Greer, A.; Foote, C. S.; Houk, K. N., Mechanism of ene reactions of singlet oxygen. A two-step no-intermediate mechanism. J. Am. Chem. Soc. 2003, 125 (5), 1319-1328; (c) Di Mascio, P.; Martinez, G. R.; Miyamoto, S.; Ronsein, G. E.; Medeiros, M. H. G.; Cadet, J., Singlet Molecular Oxygen Reactions with Nucleic Acids, Lipids, and Proteins. Chem. Rev. 2019, 119 (3), 2043-2086; (d) Clennan, E. L.; Pace, A., Advances in singlet oxygen chemistry. Tetrahedron 2005, 61 (28), 6665-6691; (e) Aubry, J. M.; Pierlot, C.; Rigaudy, J.; Schmidt, R., Reversible binding of oxygen to aromatic compounds. Acc. Chem. Res. 2003, 36 (9), 668-675.

2. (a) Dolmans, D.; Fukumura, D.; Jain, R. K., Photodynamic therapy for cancer. Nature Reviews Cancer 2003, 3 (5), 380387; (b) Ogilby, P. R., Singlet oxygen: there is indeed something new under the sun. Chem. Soc. Rev. 2010, 39 (8), 3181-3209; (c) Lovell, J. F.; Liu, T. W. B.; Chen, J.; Zheng, G., Activatable Photosensitizers for Imaging and Therapy. Chem. Rev. 2010, 110 (5), 2839-2857; (d) DeRosa, M. C.; Crutchley, R. J., Photosensitized singlet oxygen and its applications. Coord. Chem. Rev. 2002, 233, 351-371; (e) Yu, G. C.; Yu, S.; Saha, M. L.; Zhou, J.; Cook, T. R.; Yung, B. C.; Chen, J.; Mao, Z. W.; Zhang, F. W.; Zhou, Z. J.; Liu, Y. J.; Shao, L.; Wang, S.; Gao, C. Y.; Huang, F. H.; Stang, P. J.; Chen, X. Y., A discrete organoplatinum(II) metallacage as a multimodality theranostic platform for cancer photochemotherapy. Nat. Commun. 2018, 9 .

3. (a) Ghogare, A. A.; Greer, A., Using Singlet Oxygen to Synthesize Natural Products and Drugs. Chem. Rev. 2016, 116 (17), 9994-10034; (b) Nosaka, Y.; Nosaka, A. Y., Generation and
Detection of Reactive Oxygen Species in Photocatalysis. Chem. Rev. 2017, 117 (17), 11302-11336; (c) Greer, A., Christopher Foote's discovery of the role of singlet oxygen O-1(2) ((1)Delta(g)) in photosensitized oxidation reactions. Acc. Chem. Res. 2006, 39 (11), 797-804.

4. (a) Vankayala, R.; Sagadevan, A.; Vijayaraghavan, P.; Kuo, C. L.; Hwang, K. C., Metal Nanoparticles Sensitize the Formation of Singlet Oxygen. Angew. Chem. Int. Ed. 2011, 50 (45), 1064010644; (b) Xu, S.; Zhou, P.; Zhang, Z. H.; Yang, C. J.; Zhang, B. G.; Deng, K. J.; Bottle, S.; Zhu, H. Y., Selective Oxidation of 5Hydroxymethylfurfural to 2,5-Furandicarboxylic Acid Using O-2 and a Photocatalyst of Co-thioporphyrazine Bonded to gC3N4. J. Am. Chem. Soc. 2017, 139 (41), 14775-14782; (c) Sagadevan, A.; Hwang, K. C.; Su, M. D., Singlet oxygenmediated selective $\mathrm{C}-\mathrm{H}$ bond hydroperoxidation of ethereal hydrocarbons. Nat. Commun. 2017, 8; (d) de Souza, J. M.; Brocksom, T. J.; McQuade, D. T.; de Oliveira, K. T., Continuous Endoperoxidation of Conjugated Dienes and Subsequent Rearrangements Leading to $\mathrm{C}-\mathrm{H}$ Oxidized Synthons. J. Org. Chem. 2018, 83 (15), 7574-7585.

5. (a) Schweitzer, C.; Schmidt, R., Physical mechanisms of generation and deactivation of singlet oxygen. Chem. Rev. 2003, 103 (5), 1685-1757; (b) You, Y., Chemical tools for the generation and detection of singlet oxygen. Org. Biomol. Chem. 2018, 16 (22), 4044-406o; (c) Ishii, K., Functional singlet oxygen generators based on phthalocyanines. Coord. Chem. Rev. 2012, 256 (15-16), 1556-1568.

6. (a) Yamakoshi, Y.; Umezawa, N.; Ryu, A.; Arakane, K.; Miyata, N.; Goda, Y.; Masumizu, T.; Nagano, T., Active oxygen species generated from photoexcited fullerene $(\mathrm{C}-6 \mathrm{o})$ as potential medicines: O-2(-center dot) versus O-1(2). J. Am. Chem. Soc. 2003, 125 (42), 12803-12809; (b) Prat, F.; Stackow, R.; Bernstein, R.; Qian, W. Y.; Rubin, Y.; Foote, C. S., Triplet-state properties and singlet oxygen generation in a homologous series of functionalized fullerene derivatives. J. Phys. Chem. A 1999, 103 (36), 7230-7235.

7. (a) Nakamura, Y.; Suzuki, M.; Kawa, K. O.; Konno, T.; Nishimura, J., Photoreactions between 6o fullerene and various aromatic tertiary amines. J. Org. Chem. 2005, 70 (21), 8472-8477; (b) Luo, C.; Fujitsuka, M.; Watanabe, A.; Ito, O.; Gan, L. B.; Huang, Y.; Huang, C. H., Substituent and solvent effects on photoexcited states of functionalized fullerene 6o. Journal of the Chemical Society-Faraday Transactions 1998, 94 (4), 527-532; (c) Marcus, Y., Solubilities of buckminsterfullerene and sulfur hexafluoride in various solvents. J. Phys. Chem. B 1997, 101 (42), 8617-8623; (d) Priyadarsini, K. I.; Mohan, H.; Birkett, P. R.; Mittal, J. P., Identity of transients formed from chlorinated fullerenes in organic solvents: A pulse radiolysis study. J. Phys. Chem. 1996, 100 (2), 501-506; (e) Anderson, J. L.; An, Y. Z.; Rubin, Y.; Foote, C. S., Photophysical Characterization and Singlet Oxygen Yield of a Dihydrofullerene. J. Am. Chem. Soc. 1994, 116 (21), 9763-9764; (f) Malikova, R. N.; Sakhautdinov, I. M.; Ishbaeva, S. M.; Yunusov, M. S., Fullerene C-6o Derivatives as Efficient Sensitizers of Oxidation under the Mild Conditions of Atmospheric Air. Russ. J. Gen. Chem. 2017, 87 (10), 2497-2499.

8. (a) Yamamoto, M.; Fohlinger, J.; Petersson, J.; Hammarstrom, L.; Imahori, H., A Ruthenium Complex-Porphyrin-FullereneLinked Molecular Pentad as an Integrative Photosynthetic Model. Angew. Chem. Int. Ed. 2017, 56 (12), 3329-3333; (b) Wolf, M.; Herrmann, A.; Hirsch, A.; Guldi, D. M., Rigid, Branched Porphyrin Antennas: Control over Cascades of Unidirectional Energy Funneling and Charge Transfer. J. Am. Chem. Soc. 2017, 139 (34), 11779-11788; (c) Ke, X. S.; Kim, T.; Lynch, V. M.; Kim, D.; Sessler, J. L., Flattened Calixarene-like Cyclic BODIPY Array: A New Photosynthetic Antenna Model. J. Am. Chem. Soc. 2017, 139 (39), 13950-13956; (d) Favereau, L.; 
Makhal, A.; Pellegrin, Y.; Blart, E.; Petersson, J.; Goransson, E.; Hammarstrom, L.; Odobel, F., A Molecular Tetrad That Generates a High-Energy Charge-Separated State by Mimicking the Photosynthetic Z-Scheme. J. Am. Chem. Soc. 2016, 138 (11), 3752-376o; (e) Kc, C. B.; Lim, G. N.; D'Souza, F., Charge Separation in Graphene-Decorated Multimodular Tris(pyrene)-Subphthalocyanine-Fullerene Donor-Acceptor Hybrids. Angew. Chem. Int. Ed. 2015, 54 (17), 5088-5092; (f) Guldi, D. M., Fullerene-porphyrin architectures; photosynthetic antenna and reaction center models. Chem. Soc. Rev. 2002, 31 (1), 22-36; (g) Gust, D.; Moore, T. A.; Moore, A. L., Mimicking photosynthetic solar energy transduction. Acc. Chem. Res. 2001, 34 (1), 40-48; (h) Kc, C. B.; D'Souza, F., Design and photochemical study of supramolecular donoracceptor systems assembled via metal-ligand axial coordination. Coord. Chem. Rev. 2016, 322, 104-141.

9. (a) Kawase, T.; Kurata, H., Ball-, bowl-, and belt-shaped conjugated systems and their complexing abilities: Exploration of the concave-convex pi-pi interaction. Chem. Rev. 2006, 106 (12), 5250-5273; (b) Garcia-Simon, C.; Costas, M.; Ribas, X., Metallosupramolecular receptors for fullerene binding and release. Chem. Soc. Rev. 2016, 45 (1), 40-62; (c) Sygula, A., Corannulene-Adorned Molecular Receptors for Fullerenes Utilizing the pi-pi Stacking of Curved-Surface Conjugated Carbon Networks. Design, Synthesis and Testing. Synlett 2016, 27 (14), 2070-2080; (d) Makha, M.; Purich, A.; Raston, C. L.; Sobolev, A. N., Structural diversity of host-guest and intercalation complexes of fullerene C-6o. Eur. J. Inorg. Chem. 2006, (3), 507-517.

10. (a) Mejuto, C.; Escobar, L.; Guisado-Barrios, G.; Ballester, P.; Gusev, D.; Peris, E., Self-Assembly of Di-N-Heterocyclic Carbene-Gold-Adorned Corannulenes on C-6o. Chem. Eur. J. 2017, 23 (44), 10644-10651; (b) Martinez-Agramunt, V.; Gusev, D.; Peris, E., A shape-adaptable organometallic supramolecular coordination cage for the encapsulation of fullerenes. Chem. Eur. J. 2018, 24 (55), 14802-14807; (c) Martínez-Agramunt, V.; Eder, T.; Darmandeh, H.; GuisadoBarrios, G.; Peris, E., A size-flexible organometallic box for the encapsulation of fullerenes. Angew. Chem. Int. Ed. 2019, 58 (17), 5682-5686

11. (a) Cook, T. R.; Stang, P. J., Recent Developments in the Preparation and Chemistry of Metallacycles and Metallacages via Coordination. Chem. Rev. 2015, 115 (15), 7001-7045; (b) Cook, T. R.; Zheng, Y.-R.; Stang, P. J., Metal-Organic Frameworks and Self-Assembled Supramolecular Coordination Complexes: Comparing and Contrasting the Design, Synthesis, and Functionality of Metal-Organic Materials. Chem. Rev. 2013, 113 (1), 734-777; (c) Gianneschi, N. C.; Masar, M. S.; Mirkin, C. A., Development of a coordination chemistry-based approach for functional supramolecular structures. Acc. Chem. Res. 2005, 38 (11), 825-837; (d) Caulder, D. L.; Raymond, K. N., Supermolecules by design. Acc. Chem. Res. 1999, 32 (11), 975-982; (e) Chakrabarty, R.; Mukherjee, P. S.; Stang, P. J., Supramolecular Coordination: Self-Assembly of Finite Two- and Three-Dimensional Ensembles. Chem. Rev. 2011, 111 (11), 6810-6918; (f) Castilla, A. M.; Ramsay, W. J.; Nitschke, J. R., Stereochemistry in Subcomponent SelfAssembly. Acc. Chem. Res. 2014, 47 (7), 2063-2073; (g) McConnell, A. J.; Wood, C. S.; Neelakandan, P. P.; Nitschke, J. R., Stimuli-Responsive Metal-Ligand Assemblies. Chem. Rev. 2015, 115 (15), 7729-7793; (h) Fujita, M.; Ogura, K., Transitionmetal-directed assembly of well-defined organic architectures possessing large voids: From macrocycles to 2 catenanes. Coord. Chem. Rev. 1996, 148, 249-264; (i) Fujita, M., Metaldirected self-assembly of two- and three-dimensional synthetic receptors. Chem. Soc. Rev. 1998, 27 (6), 417-425; (j) Han, M.; Engelhard, D. M.; Clever, G. H., Self-assembled coordination cages based on banana-shaped ligands. Chem. Soc. Rev. 2014, 43 (6), 1848-1860.

12. (a) Gan, M. M.; Liu, J. Q.; Zhang, L.; Wang, Y. Y.; Hahn, E. F.; Han, Y. F., Preparation and Post-Assembly Modification of Metallosupramolecular Assemblies from Poly(N-Heterocyclic Carbene) Ligands. Chem. Rev. 2018, 118 (19), 9587-9641; (b) Sinha, N.; Hahn, F. E., Metallosupramolecular Architectures Obtained from Poly-N-heterocyclic Carbene Ligands. Acc. Chem. Res. 2017, 50 (9), 2167-2184.

13. Ortiz, M. J.; Agarrabeitia, A. R.; Duran-Sampedro, G.; Prieto, J. B.; Lopez, T. A.; Massad, W. A.; Montejano, H. A.; Garcia, N. A.; Arbeloa, I. L., Synthesis and functionalization of new polyhalogenated BODIPY dyes. Study of their photophysical properties and singlet oxygen generation. Tetrahedron 2012, 68 (4), 1153-1162.

14. (a) Arbogast, J. W.; Foote, C. S., PHOTOPHYSICAL PROPERTIES OF C-70. J. Am. Chem. Soc. 1991, 113 (23), 88868889; (b) Arbogast, J. W.; Darmanyan, A. P.; Foote, C. S.; Rubin, Y.; Diederich, F. N.; Alvarez, M. M.; Anz, S. J.; Whetten, R. L., PHOTOPHYSICAL PROPERTIES OF C6o. J. Phys. Chem. 1991, 95 (1), 11-12.

15. Prat, F.; Marti, C.; Nonell, S.; Zhang, X. J.; Foote, C. S.; Moreno, R. G.; Bourdelande, J. L.; Font, J., C-6o Fullerene-based materials as singlet oxygen $\mathrm{O}-2((\mathrm{1}) \operatorname{Delta}(\mathrm{g}))$ photosensitizers: a time-resolved near-IR luminescence and optoacoustic study. PCCP 2001, 3 (9), 1638-1643.

16. Hare, J. P.; Kroto, H. W.; Taylor, R., Preparation and UV visible spectra of fullerenes $\mathrm{C}_{60}$ and $\mathrm{C}_{70}$. Chem. Phys. Lett. 1991, 177 (4-5), 394-398.

17. (a) Meshnick, S. R.; Taylor, T. E.; Kamchonwongpaisan, S., Artemisinin and the antimalarial endoperoxides: From herbal remedy to targeted chemotherapy. Microbiol. Rev. 1996, 6o (2), 301-315; (b) Moncada, S.; Vane, J. R., Pharmacology and Endogenous Roles of Prostaglandin Endoperoxides, Thromboxane-A2, and Prostacylin. Pharmacol. Rev. 1978, 30 (3), 293-331.

18. Balci, M., Bicyclic Endoperoxides and Synthetic Applications. Chem. Rev. 1981, 81 (1), 91-108.

19. Preston, D.; Sutton, J. J.; Gordon, K. C.; Crowley, J. D., A Nonanuclear Heterometallic Pd3Pt6 "Donut"-Shaped Cage: Molecular Recognition and Photocatalysis. Angew. Chem. Int. Ed. 2018, 57 (28), 8659-8663.

2o. (a) Linden, S. M.; Neckers, D. C., BLEACHING STUDIES OF ROSE-BENGAL ONIUM SALTS. J. Am. Chem. Soc. 1988, 110 (4), 1257-1260; (b) Chesneau, E.; Neckers, D. C., ELECTRONTRANSFER SENSITIZED PHOTOBLEACHING OF ROSEBENGAL INDUCED BY TRIPLET BENZOPHENONES. Journal of Photochemistry and Photobiology a-Chemistry 1988, 42 (23), 269-281.

21. Semenov, K. N.; Charykov, N. A.; Keskinov, V. A.; Piartman, A. K.; Blokhin, A. A.; Kopyrin, A. A., Solubility of Light Fullerenes in Organic Solvents. J. Chem. Eng. Data 2010, 55 (1), 13-36.

22. Frimer, A. A., REACTION OF SINGLET OXYGEN WITH OLEFINS - QUESTION OF MECHANISM. Chem. Rev. 1979, 79 (5), 359-387.

23. (a) van den Heuvel, C. J. M.; Hofland, A.; Steinberg, H.; de Boer, T. J., The photo-oxidation of hexamethylbenzene and pentamethylbenzene by singlet oxygen. Recl. Trav. Chim. Pays-Bas 1980, 99 (9), 275-278; (b) Zadok, E.; Rubinraut, S.; Frolow, F.; Mazur, Y., Reactions of Dimethylbenzene, Trimethylbenzene, and Hexamethylbenzene with $\mathrm{O}(\mathrm{P}-3)$ Atoms in Liquid and on Adsorb Phases. J. Am. Chem. Soc. 1985, 107 (8), 2489-2494.

24. Arns, S.; Barriault, L., Concise synthesis of the neo-clerodane skeleton of teucrolivin a using a pericyclic reaction cascade. $J$. Org. Chem. 2006, 71 (5), 1809-1816. 
25. Valente, P.; Avery, T. D.; Taylor, D. K.; Tiekink, E. R. T., Synthesis and Chemistry of 2,3-Dioxabicyclo 2.2.2 octane-5,6diols. J. Org. Chem. 2009, 74 (1), 274-282.

26. Zozik, Y.; Salamci, E.; Kilic, A., Synthesis of eight-membered aminocyclitol analogues. Tetrahedron Lett. 2017, 58 (52), 4822-4826.

27. Staben, S. T.; Xin, L. H.; Toste, F. D., Enantioselective synthesis of gamma-hydroxyenones by chiral base-catalyzed Kornblum DeLaMare rearrangement. J. Am. Chem. Soc. 2006, 128 (39), 12658-12659.

28. Kawasumi, M.; Iwabuchi, Y., Concise Entry to Chiral 5-(4Hydroxybutyl)-2(5H)-furanone via HTIB-Mediated Novel Oxidative Fragmentation: Formal Total Synthesis of (+)Dubiusamine A. Org. Lett. 2013, 15 (7), 1788-1790.
29. Hereijgers, B. P. C.; Parton, R. F.; Weckhuysen, B. M. Cyclohexene Epoxidation with Cyclohexyl Hydroperoxide: A Catalytic Route to Largely Increase Oxygenate Yield from Cyclohexane Oxidation. Acs Catalysis 2011, 1 (10), 1183-1192.

30. Lee, R. J.; Lindley, M. R.; Pritchard, G. J.; Kimber, M. C., A biosynthetically inspired route to substituted furans using the Appel reaction: total synthesis of the furan fatty acid $\mathrm{F}_{5}$. Chem. Commun. 2017, 53 (47), 6327-6330.

31. Priest, J.; Longland, M. R.; Elsegood, M. R. J.; Kimber, M. C., An Asymmetric Synthesis of trans-Fused Butyrolactones from Endoperoxides. J. Org. Chem. 2013, 78 (7), 3476-3481.

32. Ramamurthy, V.; Sivaguru, J., Supramolecular Photochemistry as a Potential Synthetic Tool: Photocycloaddition. Chem. Rev. 2016, 116 (17), 9914-9993. 
Insert Table of Contents artwork here

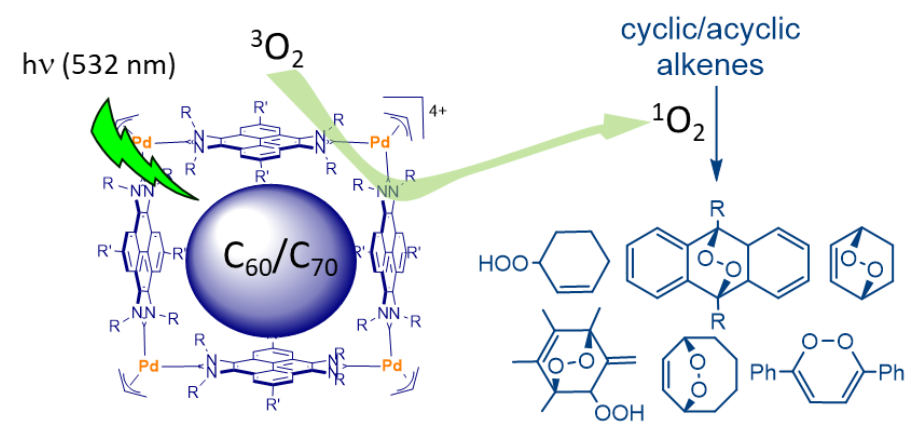

TOC synopsis: A palladium-cornered metallosquare with encapsulated fullerenes $\left(\mathrm{C}_{60}\right.$ or $\left.\mathrm{C}_{70}\right)$ behaves as an efficient singlet oxygen photosensitizer. This host:guest system is able to oxidize a variety of alkenes under very mild conditions via visible light-induced singlet oxygen generation. 